\title{
In Vitro Active vs. Field Genebank Maintenance of Sweet Potato Germplasm: Major Costs and Considerations
}

\author{
Robert L. Jarret ${ }^{1}$ \\ Southern Regional Plant Introduction Station, Agricultural Research Service, U.S. Department of Agriculture, \\ 1109 Experiment Street, Griffin, GA 30223 \\ Wojciech J. Florkowski ${ }^{2}$ \\ Department of Agricultural Economics, University of Georgia Experiment Station, 1109 Experiment Street, \\ Griffin, GA 30223
}

Increased public concern for the preservation of plant genetic diversity has resulted from a growing awareness that agricultural productivity and stability ultimately depend on plant resources that are native to a relatively few countries and that many of these plant genetic resources are threatened with extinction (Fitzgerald, 1988). Many plant genetic resources are not renewable. Conservation efforts are driven by pragmatic, concerns for the need to conserve and use plant genetic diversity to help alleviate global hunger and by an increasing recognition of our obligation to conserve these resources for future generations (Christensen, 1987). The continuing loss of the world's biological diversity has prompted several international organizations, most notably the International Board for Plant Genetic Resources (IBPGR), to organize national and international programs aimed at assembling and maintaining collections of crop germplasm. Success in this area has been impressive (Plucknett et al., 1987). However, as collections continue to increase in size and number, so do problems associated with the logistics of efficiently preserving these plant materials in a manner such that they are both secure from loss and yet available for use in crop improvement programs.

To ensure both the security and the availability of crop germplasm, a two-tier system of management has been adopted. Ideally, there exists for each crop a "base" and an "active" collection (Williams, 1984). The base collection is the vehicle for long-term conservation. Accessions in base collections are not intended for distribution. Major emphasis is placed on providing maximum security against loss, with little regard for availability. Active collections are the ve-

Received for publication 1 Dec. 1988. The cost of publishing this paper was defrayed in part by the payment of page charges. Under postal regulations, this paper therefore must be hereby marked advertisement solely to indicate this fact.

'Curator/Research Horticulturist.

${ }^{2}$ Assistant Professor. hicles for germplasm evaluation and distribution and serve as the links between conservation efforts and the user community. Management of active collections emphasizes availability and security. Base collections serve as back-ups for active collections.

The objectives of base and active collections are quite distinct; thus, strategies and technologies for preservation are also quite distinct. For example, while base collections of orthodox seed may be conserved using liquid nitrogen (Stanwood and Bass, 1981), active collections are more conveniently maintained at moderately reduced temperature and humidity. The maintenance strategy that is adopted depends on a balance between several factors, including a) the degree of security provided by a particular technology, b) the effect of that technology on availability, c) the applicability of a particular technology to the germplasm being maintained, and d) cost.

\section{MAINTENANCE OF CLONALLY PROPAGATED GERMPLASM}

The need for clonal repositories

Plant germplasm is usually collected, preserved, and distributed as seed. However, certain crops are not readily collected or preserved as seed due to problems associated with low fertility, other factors that limit or prohibit seed production, heterozygosity, or the inability to store seed of some crops at reduced temperatures and humidity. In the absence of seed production, clones are propagated and maintained in the form of trees, roots, tubers, corms, etc. in field genebanks (De Langhe, 1984; Henshaw et al., 1980; Withers, 1980). Maintenance of germplasm in field genebanks is labor-intensive and expensive (Kartha, 1985). Individual plants are subject to loss as a result of attack from insects, other pathogens, human error, and environmental variables (Henshaw et al., 1980; Newstrom, 1985). Field genebanks of many plant species serve as both the active and the base collections and, frequently, no back-up collections are available.
Germplasm maintained in field genebanks may be divided into two categories based on growth cycle and cultural characteristics, as these affect the intensity of effort (cost) required to maintain a collection, and the potential for the loss of individual accessions. Type I species includes woody and herbaceous perennials that are maintained in orchards, other types of field genebanks or botanical gardens for long periods of time requiring only periodic maintenance. Type II species include annuals, biennials, and perennials that require frequent or periodic harvesting and replanting. Frequent handling of the propagules of crops in the latter category greatly increases the potential for their loss or damage during harvest and storage and as a result of the failure of propagules to survive replanting.

Techniques that provide greater security for plant germplasm at reasonable costs must be identified. Tissue culture, cryopreservation, DNA storage technologies, and combinations of these (Stanwood and Bass, 1978; Peacock, 1984; Withers, 1984; U.S. Congress, 1987) are being investigated. Cryopreservation of vegetatively propagated germplasm is a realistic alternative for base collections as techniques are developed (Towill, 1988; Withers, 1980). The potential for the use of liquid $\mathrm{N}$ storage for active collections remains to be determined. Molecular biological approaches, such as storage of genes in genomic or cDNA libraries would, in view of the present inability to readily access these libraries, adversely affect crop improvement activities at this time if adopted as the principal storage technique. An abbreviated list of vegetatively propagated crops that may benefit from the application of biotechnological approaches for germplasm conservation is given in Table 1 .

\section{THE CASE FOR SWEET POTATO}

Sweet potato [Ipomoea batatas (L.) Lam] is among the world's most important food crops (FAO, 1986); yet its potential as a source of food, biomass, and raw material for the industrial production of starch remains underexploited. Sweet potato is clon- 
ally propagated, since many clones flower erratically or not at all in most environments (Jones, 1980). Plants grown from botanical seed rarely resemble the plants from which the seeds were harvested due to the extreme heterozygosity of the parental clones. Many clones are both self- and/or cross-incompatible (Martin, 1965). Accessions are maintained in field genebanks and propagated Field genebanks of sweet potato are subject to rapid genetic erosion as individual accessions are exposed to various environmental stresses and to attack by insect pests and soilborne diseases (Fernandez et al., 1987), Sweet potato collections in tropical areas are typically replanted and moved at 4- to 6-month intervals to reduce the incidence of soil-borne diseases and insects. This procedure is laborintensive and exposes the collection to additional biotic and abiotic hazards (Fernandez et al., 1987). In temperate areas, further losses may occur during curing and storage of the roots between growing seasons (Steinbauer and Kushman, 1971).

The development of improved sweet potato cultivars requires the existence of an accessible gene pool. However, quarantine restrictions on the international movement of sweet potato germplasm have limited the capability of established collections to support sweet potato improvement programs. The potential for the transfer of viruses remains the single most important factor limiting the distribution and conservation of sweet potato germplasm.

In vitro techniques permitting virus elimination from sweet potato (Frison and $\mathrm{Ng}$, 1981; Kuo et al., 1985; Dodds and Ng, 1987; IBPGR, 1987), and for maintenance and distribution of sweet potato germplasm (Frison, 1981: Dodds, 1987; Fernandez et al., 1987; Jarret, 1987) have been established (IBPGR, 1987). There has also been a renewed interest in germplasm collecting (De La Puente, 1987), and several large field genebanks are operational at present (Guarino and Jackson, either from vine cuttings or storage roots.

1986; Huaman, 1987; Femandez et al., 1987; Takagi, 1987). In vitro maintenance facilitates germplasm availability, principally as it affects its movement through quarantine channels (Rota et al., 1979). Germplasm availability may be further enhanced through the use of in vitro collecting techniques (Altman et al., 1987; Assy et al., 1987; Sossou et al., 1987; Withers, 1987).

\section{Sweet potato conservation in field genebanks}

Security. Curators can minimize losses from field genebanks by timely completion of field tasks. Pest control measures must be more intense, and therefore are more expensive, when a collection is grown continuously in the field as opposed to collections that are periodically harvested and the roots stored. In some locations, intensive pest control measures may be impossible due to financial or other constraints. Losses due to environmental variables such as flooding, drought, hail, poor root storage characteristics, etc., and human errors, are more difficult to manage. In temperate areas, loss of electric power during curing or storage of roots could also result in significant losses (Steinbauer and Kushman, 1971).

Availability. Sweet potato is readily propagated through rooted vine cuttings, storage roots, and rooted leaves in vivo (Martin, 1982). One or more of these plant parts is generally and continuously available. Thus, propagation material is usually available for distribution on short notice. Difficulties may arise, however, when heavy demand for propagules occurs immediately after replanting, while roots are being cured, or are in storage before replanting. In such instances, the user may be required to wait until well after replanting occurs or until after roots can be sprouted and vine cuttings produced. Yields of storable roots vary greatly between accessions. The demand for a particular accession cannot be predicted; hence, the proper volume of material to be stored for distribution

Table 1 . Selected vegetatively propagated crop species that arc maintained in field genebanks and for which in vitro techniques are either already beingused or might be used to enhance germplasm availability.

\begin{tabular}{lll}
\hline \hline & & Common English \\
Genus & Species & name \\
\hline Arachis & Various & Peanut \\
Bambusa & Various & Bamboo \\
cocos & nucifera & Coconut \\
Colocasia & esculenta & Taro \\
Dioscorea & Various & Yam \\
Frageria & Various & Strawberry \\
Gossypium & Various & Cotton \\
Ipomoea & batatas & Sweet potato \\
Lotus & comiculatas & Birdsfoot trefoil \\
Manihot & esculenta & Cassava \\
Mentha & Various & Mint \\
Muss & acuminata & Bananas \\
Muss & acuminata & Plantain \\
Muss & textilis & Hemp \\
Maranta & arundinacea & Arrow-root \\
Saccharum & Various & Sugarcane \\
Sechium & edule & Chayote \\
Solanum & Various & Potato \\
Xanthosoma & saggitifolium & Cocoyam \\
Zoysia & Various & Zoysiagrass \\
\hline
\end{tabular}

Table 2. Cost of selected machinery and equipment for field maintenance of sweet potato germplasm.

\begin{tabular}{lc}
\hline \hline \multicolumn{1}{c}{ Item } & cost $(\mathrm{US} \$)^{2}$ \\
\hline Tractor & $\$ 12,000$ \\
Mid-mount cultivator & 500 \\
Row-disk bedder & 1,100 \\
Fertilizer spreader & 500 \\
Disk harrow & 800 \\
Potato harvester & 3,100 \\
Pickup truck & $10,000^{y}$ \\
Total & $\$ 28,000$ \\
\hline
\end{tabular}

${ }^{2}$ Unit price.

Minimum price.

between growing seasons cannot be estimated accurately.

Sweet potato germplasm maintained in field genebanks cannot be maintained virus-free. Placement of clonal material previously freed of viruses into a field environment results in rapid reinfection. Virus-free propagules are considered more desirable for distribution (IBPGR, 1988); thus, conservation in field genebanks does little to enhance germplasm availability, one of the primary objectives of an active genebank. The principal advantage of field genebank maintenance is the simplicity of the technique; as a result, it is a common method of preservation (Fernandez et al., 1987; Huaman, 1987; Takagi, 1987).

Cost. Little information is available in the scientific literature concerning the cost-effectiveness of particular storage strategies. Total preservation costs are the sum of fixed and variable costs. Fixed costs include the machinery and equipment necessary for annual planting, cultivating, and harvesting (Table 2). Expensive items in this category include a vehicle for movement of materials to and from the field, a tractor, and a harvester. Variable costs include labor, gasoline, repairs, fertilizers and chemicals, insurance, etc. Anticipated labor costs might include two or three full-time employees to tend the collection [a curator and field assistant(s)] and seasonal laborers hired for timely completion of field tasks; e.g., three or four persons during harvest. Additional labor may be necessary at the beginning of the growing season for bedding of the roots that then are sprouted and from which cuttings are harvested for planting in the field. Annual cost of full-time labor for maintaining a collection of 1000 accessions is estimated at about $\$ 75,000$ to $\$ 100,000$ in the United States.

Field maintenance of a collection of sweet potato accessions requires a dedicated land area. One thousand accessions, reproduced at the rate of 20 plants per accession with a spacing of $0.3 \mathrm{~m}$ between plants and $2 \mathrm{~m}$ between rows, requires 2.5 ha. A 3-m open space between individual accessions within a row and $2 \mathrm{~m}$ between rows prevents mixing of roots during harvest and reduces competition between accessions.

Curing and storage of roots may be accomplished in a single room equipped with humidification and temperature controls. The use of a single chamber for curing and stor- 
age reduces handling of the roots and lowers the potential for losses due to mechanical damage and subsequent microbial contamination as roots are moved from one location to another. Generally, however, separate facilities are used for storage and curing since harvesting is staggered over a period of time.

The estimated cost of establishing a field genebank to conserve 1000 accessions of sweet potato, exclusive of labor costs, is about $\$ 28.00$ per accession per year. The cost of building a curing/storage chamber, or adapting an existing facility for curing and storage, would further increase the cost of maintenance per accession. The exact cost will vary widely in response to the surrounding economic environment and will differ according to the level of economic development of the country.

Accurate figures on costs associated with distribution of the germplasm (collection, packaging, transportation) are not readily available since movement of vegetative material internationally is generally between a germplasm collection and plant quarantine facilities in the receiving country. Delivery to the requestor may not occur until wellafter, in some instances many years after, materials are received by quarantine. Air freight or express courier are the preferred forms of transport since vine cuttings and roots are susceptible to rapid deterioration.

\section{Sweet potato germplasm in vitro}

References to in vitro conservation of sweet potato assume the maintenance of pathogentested materials derived from cultured meristems and maintained through reculture of axillary buds.

Security. Environmental control systems, no matter how elaborate, do fail occasionally. Tissue cultures of sweet potato are susceptible to loss as a result of sudden large fluctuations in temperature. Sweet potato cultures are generally incubated at 28 to $30 \mathrm{C}$ for optimal growth (Dodds, 1987). In our experience, a wide spectrum of sweet potato genotypes will survive several months at temperatures as low as $15 \mathrm{C}$ or as high as 35C. Maintenance below 15C, for extended periods of time, maybe lethal to some genotypes.

Human errors are more likely to cause serious problems in the operation of an in vitro genebank than failure of mechanical devices. Microbial contamination, due to poor aseptic technique, can result in a rapid deterioration and loss of cultures. Mite infestations in growth chambers or rooms may cause extensive contamination and be difficult to eradicate (Towill, 1988). In addition, more training and supervision are required during the. establishment of a collection. Placement of labels in culture vessels, and their transfer with the explants during reculture, reduces tedious hand-labeling of culture vessels. Barcoding may also be useful for inventory maintenance (Talbott and Parliman, 1987). Documentation errors are expected to occur at an equal frequency in both types of collections. Security for an in vitro collection can be increased significantly by dividing the collection into two parts and storing each in a separate growth chamber or culture room. Alternatively, the collection might be replicated at one or more locations. Division of the collection into replicates permits reculturing in phases; thus, mature plantlets are continuously available as a source of propagules for distribution.

Availability. Sweet potato cultures maybe maintained for periods of up to 2 years through regulation of the culture medium and environment (Frison, 1981). Growth rates of individual clones are highly genotype-dependent and must be recultured at 6- to 12 -month intervals. Fortunately, minimal growth maintenance techniques appear to be applicable across a wide array of sweet potato genotypes. Cultures are maintained in the USDA Sweet Potato Repository at $21 \mathrm{C}$ to retard growth. Propagation is accomplished by reculture of nodal segments. The capability to rapidly propagate selected clones is considered to be a valuable adjunct to tissue culture germplasm maintenance (Withers, 1980). Our experience indicates that in vitro plantlets are readily acclimated and that acclimatization is minimally genotype-dependent. Culture viability is readily monitored by periodic visual examination (Kartha, 1985). Once materials are freed of virus infection, they may be maintained as virus-free and are, therefore, available with minimal restrictions.

Successful receipt of germplasm transferred as tissue cultures may require that the receiver have access to facilities for the recovery of whole plants from culture. If germplasm is received as freshly cultured nodal segments, these may need to be recultured to a larger vessel and allowed to further develop over 2 weeks to 2 months. If the plant material has become etiolated in transit, it may be necessary to expose the cultures to high light intensity for some time before removing them from culture. These steps may delay immediate use of the materials.

Cost. Fixed costs of establishing a tissue

Table 3. Selected fixed-cost items associated with the establishment and operation of an in vitro germplasm conservation laboratory.

\begin{tabular}{|c|c|c|}
\hline Item name & $\begin{array}{l}\text { Approximate } \\
\text { cost }(\mathrm{US} \$)^{z}\end{array}$ & $\begin{array}{l}\text { Number } \\
\text { required }\end{array}$ \\
\hline Autoclave & $4,000-30,000$ & 1 \\
\hline Balance: toploading & 1,400 & 1 \\
\hline Balance: analytical & 1,900 & 1 \\
\hline \multicolumn{3}{|l|}{ Dissecting stereomicroscope } \\
\hline with light source & 2,000 & 1 \\
\hline Refrigerator & 600 & 1 \\
\hline $\mathrm{pH}$ meter & 600 & 1 \\
\hline Glass still for water purification & 1,850 & 1 \\
\hline General laboratory glassware & 1,500 & \\
\hline \multicolumn{3}{|l|}{ Culture vessels and racks for 10,000} \\
\hline $18 \times 150-\mathrm{mm}$ culture tubes & 0.44 & 10,000 \\
\hline vinyl-coated racks & 8 & 150 \\
\hline Stirrer/hot plate & 250 & 2 \\
\hline Laminar flow hood & $\underline{1,500-4,000}$ & 1 \\
\hline Total & $\$ 21,450$ & \\
\hline \multicolumn{3}{|l|}{ Optional equipment } \\
\hline Glassware washer & 2,800 & 1 \\
\hline Media dispenser & 1,300 & 1 \\
\hline
\end{tabular}

${ }^{2}$ Unit price. culture laboratory for preservation of sweet potato germplasm are listed in Table 3. Expensive equipment includes an autoclave and culture vessels. The minimum cost of this equipment is about $\$ 21,000$ and optional equipment costs about $\$ 4000$. The investment can be reduced by omitting a stereomicroscope and by purchasing alternative forms of glassware. A stereomicroscope is essential only if meristem culture techniques are to be used for virus elimination. An important fixed cost item is the growth chamber for maintaining cultures. A prefabricated walk-in chamber $(2.5 \times 3.0 \mathrm{~m})$ can be purchased from any of several U.S. manufacturers for about $\$ 22,000$. The chamber includes shelving, overhead lighting, temperature controls, and alarms. Additional lighting for individual shelves and photoperiod control would cost about $\$ 1500$ extra. This chamber could accommodate 30,000 to 40,000 culture tubes (3000 to 4000 accessions). A room of similar size could be constructed inside an existing building and fitted with a conventional environmental control system. The cost of constructing a culture room approximates that for a small curing/ storage chamber for roots and would be considerably less than that of a growth chamber of similar size.

Variable costs of a tissue culture laboratory include those for chemical supplies, including premixed Murashige and Skoog (1962) inorganic salts, thiamine $\cdot \mathrm{HCl}(0.4$ mg.liter $\left.{ }^{-1}\right)$, sucrose $(3.0 \%, \mathrm{w} / \mathrm{v})$, i-inositol (100 mg.liter $\left.{ }^{-1}\right)$, and Difco Bacto agar (0.7\%, $\mathrm{w} / \mathrm{v})$. These estimates are based on the use of $18 \times 150$-mm culture tubes containing $10 \mathrm{ml}$ of medium per tube and a 6-month reculture period. Twenty-thousand tubes of maintenance medium (assuming 10 cultures per accession) would be required for culture initiation of 1000 clones and reculture of these after 6 months.

The largest variable cost item is labor. A tissue culture maintenance laboratory could be run effectively by a senior scientist/curator and one or two full-time technicians. 
The cost of labor is about $\$ 75,000$ to $\$ 100,000$ annually. Two to three people are considered to be necessary for initiating and maintaining a collection of 1000 accessions, but the same number of employees could maintain a collection of several thousand accessions. The time between recultures will increase as techniques for minimal growth storage are improved and applied, further reducing the number of work hours required. The cost of maintaining a 1000 accession collection of sweet potatoes is about $\$ 22$ per accession. This estimate is slightly less than the peraccession cost in a field collection. The comparison does not include the cost of land, a curing/storage chamber necessary for a field collection, or the cost of a growth chamber for a tissue culture laboratory. Neither estimate includes costs for research or administrative support.

Tissue cultures of sweet potato are most effectively transported by air freight or are hand-carried to their destination (Ulrich, 1985). A particularly effective technique is the culture of single-node cuttings in small plastic petri dishes $(35 \times 10 \mathrm{~mm})$ containing $5 \mathrm{ml}$ of Murashige and Skoog salts (1962) and $3 \%$ sucrose, and solidified with $1 \%$ agar. The dishes are packaged in sterile plastic sleeves, sealed, and transported via air-freight. The cost of distributing culture vessels is expected to be less than or equal to the cost of express mailing roots or rooted vine cuttings.

\section{The question of genetic stability}

No discussion of in vitro germplasm storage is complete without mention of the problem of genetic instability in plant tissue cultures (D'Amato, 1975). Concerns for the loss of germplasm stored in vitro as a result of somaclonal variation (Larkin and Scowcroft, 1981) have been voiced repeatedly (Withers, 1980; Scowcroft, 1984; U.S. Congress, 1987; Towill, 1988). In. fact, this concern might be viewed as the principal factor limiting the adoption of these techniques on a broader scale. Concerns for genetic stability infield genebanks are seldom voiced, despite the fact that little information is available on the stability of clones thus maintained.

The occurrence of genetic instability in tissue culture-maintained sweet potato germplasm collections has yet to be documented, but somatic mutations area common occurrence in field plantings of this crop (Miller, 1930, 1935; Rosa, 1926; Hernandez et al., 1964; Clark and Moyer, 1988). These reports indicate that certain loci in the sweet potato genome are less stable than others and that there is considerable variation among cultivars in the incidence of somatic mutations (Hernandez et al., 1964). The leaststable loci appear to be those regulating storage root pigmentation characteristics (Hernandez et al., 1964; Clark and Moyer, 1988). Somatic mutations affecting storage root color are common, and selection for variants has resulted in the release of numerous cultivars (Elmer, 1950; Harmon, 1961; Pope and Hoover, 1966; Maryland Agr. Expt. Sta., unpublished data). Mutations affecting plant growth habit, vine pigmentation, and root quality characteristics have also been reported (Hernandez et al., 1964). Many of the mutations appear as chimeras (Clark and Moyer, 1988). The genome of sweet potato is "plastic", and reverse mutations do occur (Miller, 1935; Hernandez et al., 1964). It is a common practice to make hill selections within field plantings of popular cultivars to improve root morphological or quality characteristics, with the likelihood for success being genotype-dependent (Hernandez et al., 1964).

In general, individual accessions in field genebanks are evaluated only at infrequent intervals and for trueness to phenotype, not genotype. Loss or mutation of disease and insect resistance genes, should they occur, would go unnoticed because germplasm curators minimize the exposure of the collection to diseases, insect pests, and other stresses. It is impossible to visually monitor for the expression of resistance or susceptibility to a particular pathogen in the absence of selection pressure. Morphological variants are more readily detected, but periodic evaluation of a large field genebank of sweet potato germplasm using descriptors (IBPGR, 1981) is a formidable challenge and the data collected are of questionable value in view of the strong environmental influence on the expression of many characteristics.

If has been suggested that in vitro culture imposes a stress that might be expected to increase the potential for mutation (Scowcroft, 1984). However, it remains to be determined whether or not this stress is greater than that imposed on clones maintained in a field genebank under environmental conditions that are marginal to their survival. Growth in a field genebank also imposes a selection pressure (Hanson, 1985). Occurrence of instability appears to be more acceptable in field genebanks, since it is erroneously assumed that all variation can be detected and selected against. A similar degree of instability in vitro is apparently unacceptable, as it may be impossible to identify variants such as those affecting storage root characteristics in culture.

It seems premature at this time to suggest that mutations that occur in vitro are more likely to result in the loss of agriculturally important genes than those that occur in field genebanks (IITA, 1989). However, the inability to identify mutations affecting vegetative and root morphology in vitro suggests that a portion of the collection may need to be evaluated at scheduled intervals and cultures selected for their approximate original phenotype. Clonal identity can thus be ascertained and the in vitro collection managed as a foundation seed program. The additional effort and cost required for field evaluation or other means of monitoring phenotypic stability may be justified by increased availability of the germplasm.

Concerns for genetic instability in tissue culture collections would be partially alleviated if techniques were available for establishment of base collections. Preservation of sweet potato germplasm in a base collection would allow greater effort and resources to be devoted to the acquisition, characterization and distribution of germplasm with less concern for the maintenance of specific phenotypes, since the original genotype could be retrieved, if necessary, from the base collection. Effective base storage would also allow active collections to reduce the level of duplication of accessions within collections. Although cryopreservation promises to be [he technique of choice for a sweet potato base collection, more research is needed on techniques to stimulate flower induction and on overcoming incompatibility barriers for the production of botanical seed, which, though difficult to produce, retains its viability for long periods in storage (Jones and Dukes, 1982).

\section{Field genebanks vs. in vitro collections}

The relative lack of information on the management and operation of in vitro collections is a deterrent to their establishment (Towill, 1988). Little detailed information, with few exceptions, is available in the literature on minimal growth strategies for the conservation of individual crops (Henshaw et al., 1980). A recently initiated pilot study with cassava (Chavez et al., 1987) should help to define the major financial, scientific, and managerial aspects of in vitro germplasm maintenance. More research is needed in this area.

The practical aspects and standards of management of an in vitro collection need not be crop-specific, in contrast to facilities for maintenance in a field genebank (Hanson, 1985). The location of an in vitro maintenance laboratory may be selected on the basis of available facilities, funding, and personnel, and is not limited to a specific geography based on the cultural or horticultural characteristics of the crop. The flexibility associated with selection of a site for an in vitro facility partially alleviates concerns about the greater technical assistance required for this type of maintenance, since this factor may be taken into consideration during the planning stages. Only an in vitro collection can enhance the availability of sweet potato germplasm internationally.

An often-cited advantage of field genebanks is that there is a continuous opportunity to evaluate and characterize the germplasm in the field (Hanson, 1985). This may represent a decided advantage in dealing with crops such as perennial fruit trees with long juvenile periods. However, sweet potato can be removed from culture, acclimated, and vine cuttings produced in $<8$ weeks. In vitro maintenance of this crop does not prohibit or unnecessarily delay access to the germplasm for its characterization or evaluation. In addition, the risks associated with the use of a field collection for research purposes must be considered. Virus infection of materials maintained in field genebanks may confound efforts to estimate yield potential or disease and insect resistance characteristics accurately. An in vitro collection is not as aesthetically pleasing as a wellmaintained field genebank. In vitro mainte- 
nance may be perceived by some scientists as overly "high-tech".

In general, considerable savings in land and labor are associated with preservation of germplasm in tissue culture as compared to field genebanks. For example, preservation of 100 accessions of birdsfoot trefoil (Lotus corniculatus L.) in vitro required $0.06 \%$ of the space required for maintenance in the field (Tomes, 1979). There are also considerable economies of scale associated with the use of labor and facilities in a tissue culture laboratory. The projected personnel and a $2.5 \times 3-\mathrm{m}$ growth chamber can be used to maintain several thousand accessions. Thus, the cost of establishing and operating a laboratory per single accession is considerably reduced. Economies of scale for a field collection are less obvious. In addition, in vitro facilities and equipment are readily usable for the maintenance of other crops.

It is clearly advisable that both in vitro and field genebank collections be duplicated in one or more locations. It is also essential that all accessions be replicated within collections. For materials maintained in field genebanks, duplication in a different environment increases the likelihood for survival of selectively adapted genotypes. Duplication of in vitro collections provides security against loss as a result of culture contamination or equipment failure. However, to replace lost accessions in a field genebank at one location from stocks maintained at the duplication site, it may be necessary to deal with quarantine regulations on movement of vegetative material, thus delaying replenishment of stocks for several years or longer.

Concerns for genetic stability in culture must be addressed, but should not be used as a justification for dismissing the potential of in vitro maintenance techniques. More data are needed on the frequency of occurrence of mutations and on the types of mutations that occur in germplasm maintained in field genebanks and in tissue culture. Small changes to the phenotype may be acceptable. However, loss or a significant reduction in fecundity, or other changes that reduce the capability to readily use the germplasm, would not be acceptable. The potential for the use of restriction fragment length polymorphisms (Beckmann and Soiler, 1986) to monitor stability in vegetatively propagated germplasm collections cannot be overemphasized. Preliminary studies should focus on determining the extent of instability and on identification of variables that may be manipulated to minimize mutations.

In vitro collections are ideal as back-ups for breeders' collections or those used for educational purposes. Germplasm losses from field genebanks of breeders' collections can be extensive (Tomes, 1979). In these instances, invitro maintenance would provide additional security and reduce the cost of field maintenance, since fewer replicates of each accession would need to be maintained. Cultures need not be pathogen-tested, unless intended for distribution. In vitro collections may be useful to back-up field genebanks of numerous perennial crops. This would en- able curators of these collections to reduce the level of duplication for each accession, thus freeing space for new introductions or to reallocate funds for the conservation of other crops.

\section{CONCLUSION}

Development of efficient methods for germplasm preservation was among the priorities of land-grant universities in the United States for the fiscal year 1989 (Joint Council on Food and Agricultural Sciences, 1987). Cost-effective methods for maintaining germplasm collections are important for both developed and less-developed countries. In vitro conservation may represent a less expensive alternative where administrators find it difficult to allocate sufficient funds to support costly germplasm preservation activities. In view of existing technologies, the management of active germplasm collections demands that some compromise be made among availability, cost, and security. It is unlikely that either objective will be fully met as curators of active collections strive to ensure both conservation and availability equally. There is an urgent need to develop strategies for the conservation of these crops in base collections.

There continues to be concern for the genetic stability of vegetatively propagated crop germplasm maintained in vitro (U.S. Congress, 1987), but there are no data yet available to suggest that the genetic stability of these materials is less than that of germplasm maintained in the field. Neither is there a clear consensus on what factors might confer instability on in vitro plantlets. Mutation frequencies are purportedly proportional to the rate of cell division (Henshaw et al., 1980). However, restricting the rate of cell division also imposes a stress on the growing plantlet, which may increase the potential for mutation (Scowcroft, 1984).

Is the principal purpose of an active collection to maintain and distribute co-adaptive gene complexes for crop improvement research, or is it to maintain the rigid clonal identity of each accession? Should equal concern be given to the maintenance of the clonal identity of land races and primitive cultivars as is given to elite cultivars and breeding lines? Would the infrequent occurrence of somatic mutations, should they occur, result in a significant loss of desirable genes or gene complexes? Are in vitro active collections museums for maintenance of clonal identity or do the advantages associated with increased availability outweigh concerns for potentially low levels of somaclonal variation? Is it reasonable to ignore a maintenance technique that may be more cost-effective and may offer equal security when compared to conventional approaches? These, and other, questions relative to the function and administration of active genebanks await answers.

On a pragmatic note, the efficacy of plant germplasm conservation efforts tend to be judged on the extent of exchange and use that takes place (Scowcroft, 1984). It behooves curators of active genebanks to identify, develop, and use techniques that ensure the greatest availability of germplasm in their charge. Scientifically competent curators are a prerequisite for success.

\section{Literature Cited}

Altman, D. W., P.A. Fryxell, and C.R. Howell. 1987. Development of a tissue culture method for collecting wild germplasm of Gossypium. FAO/IBPGR Plant Genet. Rcs. Nwsl. 71:1415 .

Assy, B., T. Durand-Gasselin, and C. Pannetier. 1987. Use of zygotic embryo culture to collect germplasm of coconut (Cocos nucifera $\mathrm{L}$.). FAO/ IBPGR Plant Genet. Res. Nwsl. 71:4-10.

Beckmann, J.S. and M. Soller. 1986. Restriction fragment length polymorphisms and genetic improvement of agricultural specics. Euphytica 35:111-124.

Chavez, R., W.M. Rota, and J.T. Williams. 1987. IBPGR-CIAT collaborative project on a pilot $\mathrm{m}$ vitro active genebank. FAO/IBPGR Plant Genet. Res. Nwsl. 71:11-13.

Christensen, E. 1987. Genetic ark: A proposal to preserve genetic diversity for future generations. Stanford Law Rev. 40:279-321.

Clark, C.A. and J.W. Moyer. 1988. Compendium of sweet potato diseases. American Phytopathology Society Press, St. Paul, Minn.

D'Amato, F. 1975. The problems of genetic stability in plant tissue and cell culture, p. 333348. In: O.H. Frankel and J.G. Hawkes (eds.). Crop genetic resources for today and tomorrow. Cambridge University Press, Cambridge, U.K.

De Langhe, E.A.L. 1984. The role of in vitro techniques in germplasm conservation, p. 131137. In: J.H.W. Holden and J.T. Williams (eds.). Crop genetic resources: Conservation and evaluation. George Allen and Unwin, Boston.

De La Puente. F. 1987. Progress m exploration and collection of sweet potato genetic resources: The IBPGR/CIP project. Exploration, maintenance and utilization of sweet potato genetic resources. Rpt. 1st Plan. Conf., Intl. Potato Center, Lima, Peru. p. 75-100.

Dodds, J.H. 1987. Review of in vitro propagation and maintenance of sweet potato germplasm. Exploration, maintenance and utilization of sweet potato genetic resourccs. Rpt. 1st Plan. Conf. Intl. Potato Center, Lima, Peru. p. 185-192.

Dodds, J.H. and S.Y.C. Ng. 1987. In vitro methods for pathogen elimination and international distribution of sweet potato germplasm. Exploration, maintenance and utilization of sweet potato genetic resources. Rpt. 1st Pkm. Conf., Intl. Potato Center, Lima, Peru. p. 323-330.

Elmer, O.H. 1950. Sweetpotatoes in Kansas. Kansas Agr. Expt. Sta. Bul. 341.

FAO. 1986.1985 Production Yearbook. Food and Agricultural Organization of the United Nations. vol. 37, FAO, Rome, Italy.

Fcrnandez, G. C. J., J.H. Lu, and Y.K. Huang. 1987. Status of sweet potato collections maintained at AVRDC. Exploration, maintenance and utilization of sweet potato genetic resources. Rpt. 1st Plan. Conf., Intl. Potato Center, Lima, Peru. p. 129-140.

Fitzgerald, P.J. 1988. Genetic considerations in the collection and maintenance of germplasm. HortScience 23:84-85

Frison, E.A. 1981. Tissue culture: A tool for improvement and international exchange of tropical root and tuber crops. Intl. Inst. Trop. Agr. Res. Briefs 2:1-4.

Frison, E.A. and S.Y. Ng. 1981. Elimination of sweet potato virus disease agents by meristem tip culture. Trop. Pest Mgt. 27:452-454.

Guarino, L. and G.V. H. Jackson. 1986. Describing and documenting root crops in the south 
pacific. FAO. RAS/83/001. Suava, Fiji. Field Dec. 12.

Hanson, J. 1985. Methods of storing tropical root crop germplasm with special reference to yam. FAO/IBPGR Plant Genet. Res. Nwsl. 64:2432.

Harmon, S.A. 1961. Red Earlysweet: A new early maturing high quality sweet potato. Georgia Agr. Expt. Sta. Mimeo Ser. N.S. 121.

Henshaw, G. G., J.F. O'Hara, and R.J. Westcott. 1980. Tissue culture methods for the storage and utilization of potato germplasm, p. 71-76. In: D.S. Ingram and J.P. Helgeson (eds.). Tissue culturc methods for plant pathologists. Blackwell, Oxford, U.K.

Hernandez, T. P., T. Hernandez, and J.C. Miller. 1964. Frequency of somatic mutations in several sweet potato varieties. Proc. Amer. Soc. Hort. Sci. 85:430-433.

Huaman, Z. 1987. Current status on the maintenance of sweet potato germplasm. Exploration, maintenance and utilization of sweet potato genetic rcsources. Rpt. 1st Plan. Conf., Intl. Potato Center, Lima, Peru. p.101-120.

IBPGR. 1981. Genetic resources of sweet potato. Intl. Board for Plant Genet. Resources, Rome, Italy.

IBPGR. 1987. Meristem-tip culture and virus indexing of sweet potatoes. Intl. Board for Plant Genet. Resources, Rome, Italy.

IBPGR. 1988. Conservation and movement of vegetatively propagated germplasm: In vitro culture and disease aspects. Intl. Board for Plant Genet. Resources, Rome, Italy.

IITA. 1989. Sweet potato field cuttings compared with in vitro plantlets. Intl. Inst. of Tropical Agriculture Annu. Rpt. 1987/88. Ibadan, Nigeria.

Jarret, R.L. 1987. The U.S. sweet potato repository. Exploration, maintenance and utilization of sweet potato genetic rcsources. Rpt. 1st Plan. Conf., Intl. Potato Center, Lima, Peru. p. 121128.

Joint Council on Food and Agricultural Sciences (U.S.). 1987.1989 Fiscal year priorities for research, extension and higher education. June.

Jones; A. 1980. Sweet potato. p. 645-656. In: W.H. Fehr and H.H. Hadley (eds.). Hybridization of crop plants. Amer. Soc. Agron. and Crop Sci. Soc. of Amer. Madison, Wis.

Jones, A. and P.D. Dukes. 1982. Longevity of stored seed of sweet potato. HortScicncc 17:756757.

Kartha, K.K. 1985. Meristem culture and germ. plasm preservation, p.115-134. In: K.K. Kar. tha (ed.). Cryopreservation of plant cells and organs. CRC Press, Boca Raton, Fla.

Kuo, C. G., B.J. Shen, M.J. Shen, S.K. Green and D.R. Lee. 1985. Vuus-free sweet potato storagc roots derived from meristem-tips and leaf cuttings. Scientia Hort. 26:231-240.

Larkin, P.J. and W.R. Scowcroft. 1981. Soma clonal variation - a novel source of variability from cell culture for plant improvement. Theor. Applied Genet. 60:197-214.

Martin, F. 1965. Incompatibility in the sweet potato. A review. Econ. Bet. 19:406-415.

Martin, F.W. 1982. Technique for rooting sweet potato leaves. HortScience 17:386-396.

Miller, J.C. 1930. A study of mutations of the Porto Rico sweet potato. Proc. Amer. Soc. Hort. Sci. 28:343-346.

Miller, J.C. 1935. Further studies of mutations of the Porto Rico sweet potato. Proc. Amer. Soc. Hort. Sci. 33:460-465.

Murashige, T. and F. Skoog. 1962. A revised medium for rapid growth and bioassays with tobacco tissue cultures. Physiol. Plant. 15:473497.

Newstrom, 1985. Collcction of chayote and its wild relatives. FAO/IBPGR Plant Genet. Res.
Nwsl. 64:14-20.

Peacock, W.J. 1984. The impact of molecular biology on genetic resources, p. 268-275. In: J.H.W. Holden and J.T. Williams (eds.). Crop genetic resources: Conservation and evaluation. George Allen and Unwin, Boston.

Plucknett, D. L., N.J.H. Smith, J.T. Williams, and N.M. Anishetty (eds.). 1987. Genebanks and the world's food. Princeton Univ. Press, Princeton, N.J.

Pope, D.T. and M. W. Hoover. 1966. N.C. Porto Rico 198. North Carolina Agr. Expt. Sta. Bul. 429.

Rota, W. M., J.E. Bryan, and M.R. Rota. 1979. Tissue culture for the international transfer of potato genetic resources. Amer. Potato J. 56:18.

Rosa, J.T. 1926. Mutations in the sweet potato. J. Hered. 17:167-168.

Scowcroft, W.R. 1984. Genetic variability in tissue culture: Impact on conservation and utilization. AGPG:IBPGR/84/152, IBPGR Secretariat, Rome, Italy.

Sossou, J., S. Karunaratne, and A. Kovoor. 1987. Collecting palm: In vitro explanting in the field. FAO/IBPGR Plant Genet. Res. Nwsl. 69:1718.

Stanwood, P.C. and L.N. Bass. 1978. Ultracold preservation of seed germplasm. Plant cold hardiness and freezing stress: Mechanism and crop implications. Academic, New York. p. 361371.

Stanwood, P.C. and L.N. Bass. 1981. Seed germplasm preservation using liquid nitrogen. Seed Sci. Technol: 9:423-437.

Steinbauer, C.E. and L.J. Kushman. 1971. Sweet potato culture and diseases. U.S. Government Printing Office, Washington, D.C. USDA Hdbk. 388.

Takagi, H. 1987. Sweet potato collections in Papua
New Guinea. Exploration, maintenance and utilization of sweet potato genetic resources. Rpt. 1st Plan. Conf., Intl. Potato Center, Lima, Peru. p. $147-158$.

Talbott, H.-J. and B. Parliman. 1987. Using bar code technology for horticultural research and plant inventory activities. HortSciencc 22:359369.

Tomes, D.T. 1979. A tissue culture process for propagation and maintenance ofLotus corniculatus genotypes. Can. J. Bet. 57:137-140.

Towill, L.E. 1988. Genetic considerations for germplasm preservation of clonal materials. HortSciencc 23:91-97.

Ulrich, J.M. 1985. Storage and shipping of plant cells, p. 1-32. In: E. Kurstak (cd.). Techniques in the life sciences, $\mathrm{Cl}$, Techniques in setting up and maintenance of tissue and cell cultures. Elsevier, Amsterdam.

U.S. Congress. 1987. Office of Technology Assessment, Technologies to maintain biological diversity. U.S. Government Printing Office, Washington, D.C.

Williams, J.T. 1984. A decade of crop genetic resources research, p. 1-17. In: J.H.W. Holden and J.T. Williams (eds.). Crop genetic resources: Conservation and evaluation. George Allen and Unwin, Boston.

Withers, L.A. 1980. Tissue culture storage for genetic conservation. AGP:IBPGR/80/8, Intl. Board for Plant Genet. Resources, Rome, Italy.

Withers, L. 1984. Germplasm conservation in vitro: Present state of research and its application, p. 138-157. In: J.H.W. Holden and J.T. Williams (eds.). Crop genetic resources: Conservation and evaluation. George Allen and Unwin, London.

Withers, L.A. 1987. In vitro methods for collecting gcrmplasm in the field. FAO/IBPGR Plant Genet. Res. Nwsl. 69:2-6. 